\title{
Opening Artists' Books to the User: An Example with Potential Approaches
}

ARTISTS' BOOKS ARE AN INCREASINGLY POPULAR collecting area both for art libraries and for special collections. Their experimentation with the book form and emphasis on hand techniques for production dovetail nicely with early printed book collections, highlighting modern approaches to bookmaking techniques that have been used for hundreds of years. The 2010 OCLC Research Survey Taking Our Pulse identified artists' books as "the specific area most frequently named" for new collecting in special collections. ${ }^{2}$ In this paper we will discuss a specimen artist's book and various issues and approaches to cataloging it.

Artists' books pose particular challenges to special collections catalogers, who are primarily trained in early printed book cataloging, rather than art cataloging. While early printed book description, with its emphasis on the book as an object, does give some preparation for dealing with artists' books, artists' books present a number of vocabulary terms and techniques that are not found in early printed books.

The fact that there are no standards governing the cataloging of artists' books compounds these challenges; they are not specifically mentioned in AACR2, RDA, Descriptive Cataloging of Rare Materials (Books), or Descriptive Cataloging of Rare Materials (Graphics). The Art Libraries Society of the UK and Ireland (ARLIS) published Artists' Books: A Cataloguer's Manual in 2006, which does give specific instructions following AACR2 rules, but it is not widely used by special collections catalogers.

Any of the standards listed above can be used to catalog artists' books, but none of them address the fundamental philosophical challenge of cataloging artists' books: how and to what extent to represent the artist's intention, assuming that is known. The authors - a rare book cataloger and a book artist—will look at the interplay between the artist's creative process and the catalog description. How well does the

1. Originally presented as "What the Heck Is This Thing? Opening Artists' Books to the User" at the 2013 RBMS Preconference in Minneapolis, MN. Ann K.D. Myers is a rare books cataloger at Stanford University. Her father, William Andrew Myers, is a book artist and printmaker.

2. Jackie M. Dooley and Katherine Luce, Taking Our Pulse: The OCLC Research Survey of Special Collections and Archives (Dublin, Ohio: OCLC Research, 2010): 27. 
description serve both users of the collection and the artists' vision for their work? Artists and catalogers have a shared goal: both want the widest possible audience for the artist's work. The cataloger's challenge is achieving that goal without misrepresenting the artist's intention.

\section{Challenges of Cataloging Artists' Books}

The first challenge when cataloging artists' books is defining what constitutes an artist's book. Scholarly definitions vary, and they tend to exclude certain genres of book arts. Betty Bright, in her survey of the field, offers this perspective:

Simply stated, an artist's book is a book made by an artist. To create it an artist either executes each step of a book's production or works closely with others to give form to a vision.... Every aspect of the book-from content to materials to format-must respond to the intent of the artist and cohere into a work that is set in motion with a reader's touch. ${ }^{3}$

This supports librarians' tendency to prefer inclusion over the risk of excluding a critical work. ${ }^{4}$ The 2006 ARLIS manual for cataloging artists' books takes the term "to encompass the full gamut of books produced by artists, from unique handmade fantasy structures to more traditional mass-produced books in codex form."

The format of artists' books also presents a challenge, as they notoriously do not fall easily into only one category of material. Catalogers must be flexible in applying the cataloging rules for different formats, including monographs, graphic material, and realia. ${ }^{6}$ Furthermore, the visual and physical nature of artists' books does not lend itself to strictly bibliographic description, and catalogers must rely on prose notes to describe the visual and physical characteristics of the items. ${ }^{7}$ While this process is not that different from certain aspects of rare book cataloging, the vocabulary used to describe artists' books is very different.

While physical description is a fairly obvious challenge, less obvious are those related to bibliographic description and subject access. Many artists' books deliberately obscure or omit such bibliographic information as title, creator, and publication information. Extrinsic information, such as artist's statements, dealer descriptions,

3. Betty Bright, No Longer Innocent: Book Art in America: 1960-1980 (New York: Granary Books, 2005), 3.

4. Michelle A. Stover, "Categorizing the Unique: Analyzing Artists' Books for a Framework of Description" (master's paper, University of North Carolina, Chapel Hill, 2005): 11.

5. Maria White, Patrick Perratt, and Liz Lawes, Artists' Books: A Cataloguer's Manual (London: ARLIS/UK \& Ireland, 2006), 7.

6. Nina Schneider, "Cataloging Artists Books" (paper presented at the 47th Annual RBMS Preconference, June 21, 2006), 1.

7. Andrea Chemero, Caroline Seigel, and Terrie Wilson, "How Libraries Collect and Handle Artists' Books," Art Documentation 19, no. 1 (Spring 2000): 23. 
invoices, publisher websites, and even communication with the artists themselves may be necessary to record basic identifying information. ${ }^{8}$

Even the choice of main entry or creator is not necessarily straightforward. While cataloging practice tends to emphasize the role of the author of the text, that person may not be the creator of the work as a whole (for example, if an artist has taken a text and used it as the starting point for the imagery and book design). Johanna Drucker recommends asking who initiated the artist's book: The artist? The publisher? The author? ${ }^{9}$

The cataloger must also decide how many added access points to include in the record. The author and artist are obvious choices, as is perhaps the publisher, but often the colophon includes the names of binders, papermakers, type casters, type setters, printers, and print shop assistants. When possible, it is best to err on the side of inclusivity. One never knows if a patron might be searching for a particular name, or if one of those assistants will later become a prominent figure in the artists' book world. ${ }^{10}$ Catalogers should pay particular attention to added access points for presses and artists local to their area, especially if the local connection is the reason the book was purchased for the collection.

Perhaps the most difficult aspect of cataloging artists' books is providing adequate and accurate subject access. Much of the challenge comes from trying to describe a visually oriented medium through a record structure designed for text. Library of Congress Subject Headings are often insufficient to describe book art features and, in some cases, are actually misleading. ${ }^{11}$ Genre headings taken either from the Library of Congress headings or other sources, such as the Getty's Art and Architecture Thesaurus, can help provide controlled vocabulary for aspects of the physical structure and illustration medium described in the notes fields. However, a cataloger who does not have a background in art or the various crafts that make up the book arts can find it difficult to determine the best terms to use. Furthermore, not all catalog interfaces allow a distinction in searching between subject and genre terms, thus conflating terms indicating what a work is about and what it is. ${ }^{12}$

At the very least, the term "Artists' books" should be used in the record, whether as subject or genre; when used as a subject term, it should be further subdivided

\footnotetext{
8. Simon Ford, "Artists' Books in UK and Eire Libraries," Art Libraries Journal 18, no. 1 (1993): 19; White, Perratt, and Lawes, Artists' Books: A Cataloguer's Manual, 7.

9. Johanna Drucker, "Critical Issues/Exemplary Works,” The Bonefolder 1, no. 2 (Spring 2005): 5.

10. Schneider, "Cataloging Artists Books," 9.

11. Mary Anne Dyer and Yuki Hibben, "Developing a Book Art Genre Headings Index," Art Documentation: Journal of the Art Libraries Society of North America 31 (Spring 2012): 59.

12. Schneider, "Cataloging Artists Books," 7.
} 
by the term "Specimens." 13 Individual libraries may wish to use subject headings to document why the book was collected; for example, to highlight a particular binding structure, or the work of a local press. Whether to apply full subject analysis to artists' books is a question for local institutional policy and may lead to some complicated philosophical issues. It may not be possible to determine what an artist's book is really "about" in the traditional sense of subject analysis. The images may be clearly identifiable as, say, cats, but is the work really about cats, or are images of cats being used to express some larger or quite different concept?

There is debate within the artists' book cataloging community over this issue.

Some argue that, by providing subject headings about the supposed content of the book, the cataloger risks misrepresenting the artist's intention and furthermore veers into interpreting the work, which could affect how a user perceives the work upon viewing it in person. ${ }^{14}$ The argument continues that it is not the cataloger's role to become an art critic or to ascribe meaning or intent. ${ }^{15}$ Ford, commenting on a similar debate in the museum world, disagrees: "a context-less vacuum in which to view art does not exist." 16

The purpose of the library catalog is to provide the user with information to access the book. The cataloger must consider whether subject analysis will aid that end. All catalog records provide some degree of interpretation, whether describing artists' books or math textbooks. It may be not only the cataloger's interpretation that finds its way into the catalog record, either; it may be the acquisition librarian's, the bookseller's, or even that of artist. Ultimately, each library must decide on a local policy regarding interpretation. ${ }^{17}$

\section{Alpha to Omega}

\section{DESCRIPTION}

Alpha to Omega: On the Universe is a handprinted artist's book consisting of twentyfour paired pages (diptychs), one for each of the twenty-four letters of the Greek alphabet. The 14" by 20 " leaves are unbound, contained in a clamshell box whose cherry wood spine is hinged at the top, allowing it to be opened and fastened as a support. The open box thus functions as a display stand (see figure 1). Each diptych consists of a text page containing a primary text and a commentary on that text, as well as an image page consisting of a relief print (see figure 2). The three-color

13. White, Perratt, and Lawes, Artists' Books: A Cataloguer's Manual, 13; Schneider, "Cataloging Artists Books," 10 .

14. Timothy Shipe, "The Monographic Cataloger and the Artists' Book: The Ideal Reader," Art Documentation (Spring 1991): 24.

15. Stover, "Categorizing the Unique," 15, 25.

16. Ford, "Artists' Books in UK and Eire Libraries," 19.

17. White, Perratt, and Lawes, Artists' Books: A Cataloguer's Manual, 9-10, 12. 
text is printed from hand-set metal type, 36 and 18 point Valiant, with headers and footers in 30 point Piranesi. Large initial letters are wood engravings based on an old English black letter alphabet. The image pages are relief printed in a variety of media, including linoleum cut, woodcut, wood engraving, type, and printing from found objects. The paper is Rives BFK, a heavyweight white art paper. The limited edition will consist of 12 copies, plus a number of loose prints and text pages.

Figure 1.

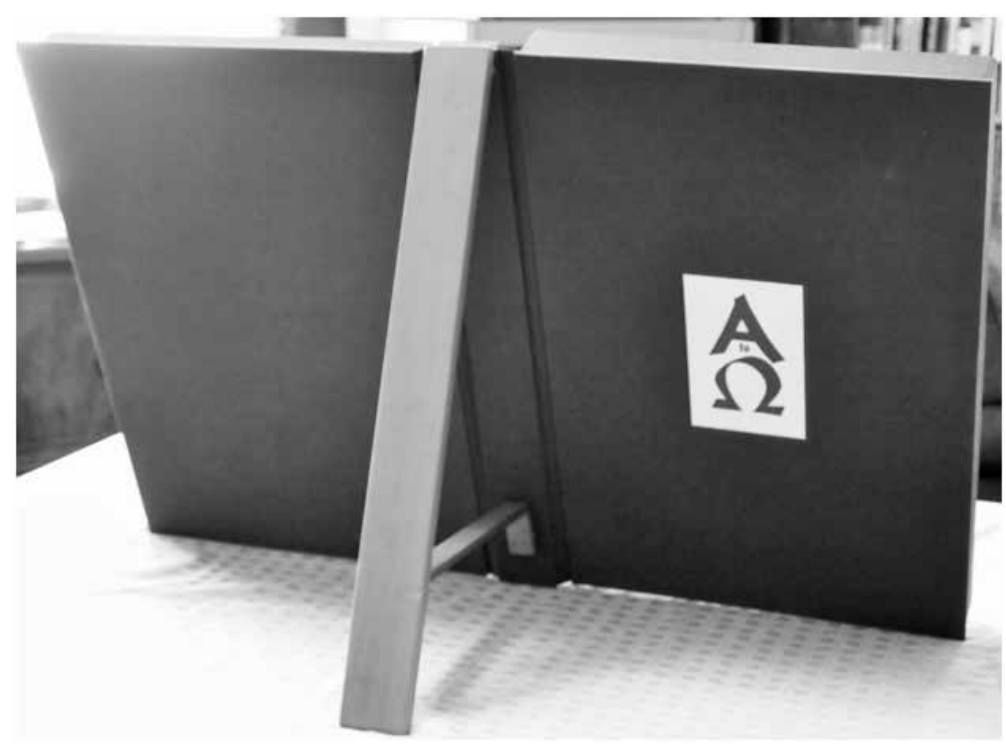

Figure 2.

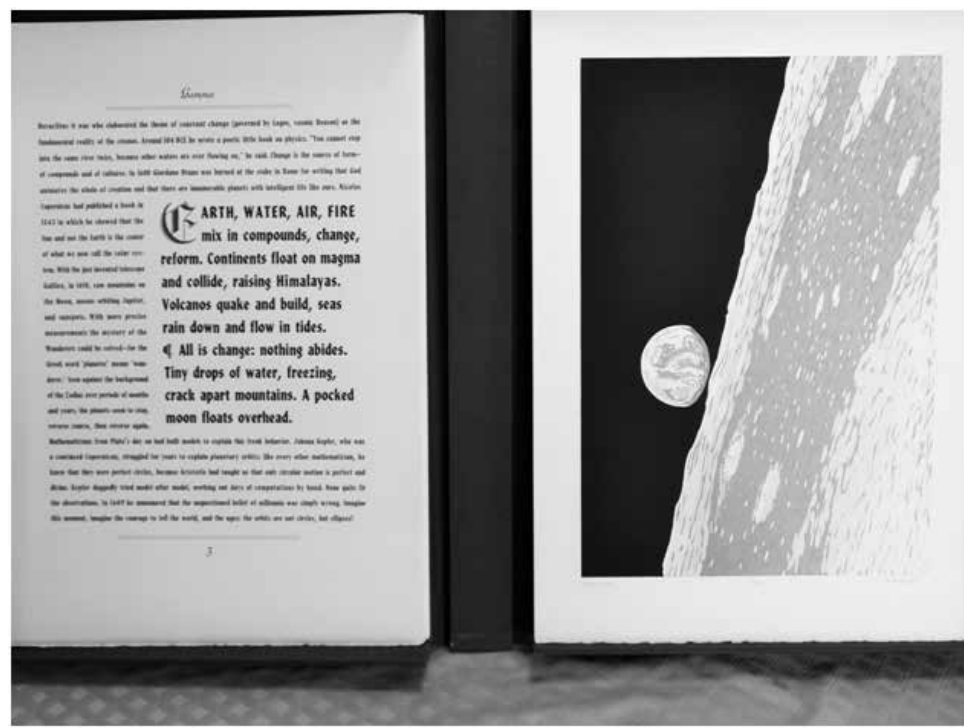




\section{Content}

The content of the book is presented as a main text surrounded by commentary; except for the first text page, Alpha, which quotes the first verses of Genesis, all the text is by the artist. Each of the primary texts is a prose poem. Themes include creation, the history of civilization, science and technology, warfare, orientation, infinity, completeness, microcosm/macrocosm, and other randomly dispersed topics that collectively treat aspects of the world from beginning to end. The 24 diptychs divide into eight sections, titled Genesis (Beginning), Gaia (Earth), Anthropos (Humanity), Techne (Craft), Polis (Civilization), Polemos (War), Apokalypsis (Revelation), and Hen (Unity). In creating the text, the author has made use of a broad range of sources, including ancient to contemporary philosophic, religious, scientific, and literary ideas-East and West. The introduction is a meditation on the idea of an infinite book.

\section{IMAGERY}

The images accompanying the text pages are relief prints, including abstracts, landscapes, and fantasy visions. The artist's dreams played a significant role in providing material for these pages. The imagery is not necessarily illustrative of the paired text but is meant to take the reader further into the mental space created in the texts. The artist's visual styles have been influenced by his training as a wood engraver but also by such artists as Albrecht Dürer, Helen Frankenthaler, and Marc Chagal. Throughout the creation of the work, the artist approached the imagery in the project as a series of experiments in relief printmaking, the text pages intended to exemplify fine press printing from moveable type.

\section{Process}

All the text is printed from handset metal type. Both the text and the images were printed on one of two presses, a Vandercook cylinder proofing press built in 1965 and a Reliance iron hand press dating from about 1895 . Nearly all leaves were printed dry, as dampening distorts the paper and makes precise registration for multiple color runs difficult. The image pages include woodcuts, wood engravings, pressure prints, mixed media, and printings from such found objects as a computer circuit board. Block materials included linoleum, plywood, endgrain maple, Formica, Corian, and acrylic plastic. Book artists have used the full gamut of printmaking processes as well as commercial offset printing in their works. In the case of Alpha to Omega, relief printing offered the most versatile process for experimenting with various materials. 


\section{Cataloging Alpha to Omega}

How should we represent an object as complex as Alpha to Omega in a catalog record? How much of the information presented above makes it into the description, if indeed all of that information is available to the cataloger? Annie Herlocker's 2012 survey of academic libraries with artists' book collections indicated that students are most likely to request artists' books by searching for specific binding types, subject matters, or materials, making the structure of the book at least as important as the subject matter and intellectual content. ${ }^{18}$ However, Timothy Shipe questions whether detailed physical description might "diminish its initial aesthetic or artistic impact on the user." ${ }^{19}$ This may be a valid question in a museum environment; but, in a library research environment where the collection is not on display, if users cannot find the items they are interested in, those items will never be viewed.

What follows is a brief catalog record for Alpha to Omega, created using only information gleaned directly from the book itself. This record is acceptable, if not ideal, and it is similar to many of the records for artists' books currently found in WorldCat.

\section{Brief Record}

Title: Alpha to omega : on the universe / William Andrew Myers.

Author/Creator: Myers, William A., 1944-

Language: $\quad$ English

Imprint: $\quad$ [St. Paul, Minn.] : Piano Press, [2013]

Format: $\quad$ Book

[60] leaves : col. ill. ; $51 \mathrm{~cm}$. in box $54 \times 40 \times 6 \mathrm{~cm}$.

Note: Title page includes woodcuts of the Greek characters "alpha" and "omega."

Note: Title page and text in black, brown, and blue. Woodcut initial letters.

Note: $\quad 24$ diptychs of text and image, one for each letter of the Greek alphabet, divided into 8 sections with separate title pages for each section. Loose sheets held in blue cloth clamshell box with wooden spine hinged to open as a support, allowing the open box to serve as a display stand.

Note: "The three-color text is printed from hand set metal type, 36 and 18 point Valiant, with headers and footers in 30 point Piranesi.

18. Annie Herlocker, "Shelving Methods and Questions of Storage and Access in Artists' Book Collections," Art Documentation: Journal of the Art Libraries Society of North America 31 (spring 2012): 70.

19. Shipe, "The Monographic Cataloger and the Artists' Book," 24. 
The image pages are relief printed in a variety of media, including linoleum cut, woodcut, wood engraving, type, and printing from found objects. The paper is Rives BFK, a heavyweight white art paper. The limited edition will consist of 12 copies, plus a number of loose prints."-Colophon

Local note: $\quad$ Special Collections \& University Archives copy 1: No. 1/12, signed by artist.

Contributor: Piano Press, publisher.

Subjects: $\quad$ Artists' books-Minnesota-Specimens.

Genres: $\quad$ Artists' books.

As recommended in much of the literature, there are prose notes providing physical description, and a quotation from the colophon about the materials used in the book's production. The only subject and genre headings are for artists' books; there is no controlled vocabulary access to details of the book's structure, illustration medium, or other physical details. Keyword searching could elicit some of these details from the prose notes, but there is no access to the intellectual content of the book at all.

Is this record sufficient? It would provide access to anyone doing a general search for artists' books and might appear in keyword searches for woodcuts, wood engraving, clamshell box, etc. It is easily found by someone already interested in this particular artist or press. However, the lack of access to its intellectual content fails to fully describe what the work is, and controlled vocabulary for the physical description would also aid in discovery. The 2006 ARLIS manual on cataloging artists' books advocates cataloging to the greatest depth or highest level that the available information allows, using all tools and resources available. In addition to the book itself, the cataloger should consult published sources, dealer's descriptions, other library catalogs, and the acquisitions librarian should record information from the artist and pass that on to the cataloger as well. Particularly in cases where an artist's book does not include a colophon, an artist's statement about the conception of the work, the materials used, printing techniques, and binding can be immensely helpful to the cataloger. With all of this information available, the cataloger can then make flexible use of notes fields and controlled vocabularies to expand the record and increase access. ${ }^{20}$

Here is a fuller catalog record for Alpha to Omega. Using the brief record above as a starting point, it makes full use of the artist's statement and other extrinsic sources of information, as well as providing more controlled vocabulary, both for the physical description and the intellectual content.

20. White, Perratt, and Lawes, Artists' Books: A Cataloguer's Manual, 15-16. 


\section{Full Record}

Title: Alpha to omega : on the universe / William Andrew Myers.

Author/Creator: Myers, William A., 1944-

Language: $\quad$ English

Imprint: [St. Paul, Minn.] : Piano Press, [2013]

Format: $\quad$ Book

[60] leaves : col. ill. ; $51 \mathrm{~cm}$. in box $54 \times 40 \times 6 \mathrm{~cm}$.

Note: Title page includes woodcuts of the Greek characters "alpha" and "omega."

Note: $\quad$ Title page and text in black, brown, and blue. Woodcut initial letters.

Note: $\quad 24$ diptychs of text and image, one for each letter of the Greek alphabet, divided into 8 sections with separate title pages for each section. Loose sheets held in blue cloth clamshell box with wooden spine hinged to open as a support, allowing the open box to serve as a display stand.

Note: "The three-color text is printed from hand set metal type, 36 and 18 point Valiant, with headers and footers in 30 point Piranesi. The image pages are relief printed in a variety of media, including linoleum cut, woodcut, wood engraving, type, and printing from found objects. The paper is Rives BFK, a heavyweight white art paper. The limited edition will consist of 12 copies, plus a number of loose prints."-Colophon.

Note: $\quad$ Clamshell box made by Kent Aldrich; wooden spine made by Elizabeth Barnard.

Contents: Genesis/Beginning_Gaia/Earth—Anthropos/HumanityTechne/Craft—Polis/Civilization—Polemos/War-Apokalypsis/Revelation-Hen/Unity.

Local note: $\quad$ Special Collections \& University Archives copy 1: No. 1/12, signed by artist.

Contributors: Aldrich, Kent, binder.

Barnard, Elizabeth.

Piano Press, publisher.

Subjects: Artists' books-Minnesota-Specimens.

Relief printing-Specimens.

Letterpress printing-Specimens.

Bible. Genesis.

Creation.

Cosmology.

Humanity.

Techne (Philosophy). 
Technology.

Civilization.

War.

Revelation.

Genres: $\quad$ Artists' books.

Typefaces (Type evidence)—Valiant.

Typefaces (Type evidence)—Piranesi.

Linocuts (prints)

Woodcuts (prints)

Wood engravings (prints)

Found objects.

While this record clearly provides more avenues for access to this book, the drawback is the amount of time a record of this level of detail takes to create. If the artist's statement were not included with the book when it arrived on the cataloger's desk, time might be spent contacting the acquisitions librarian, searching the Internet, and perhaps contacting the artist personally. The controlled vocabulary terms are taken from three different sources, creating extra steps in searching for and identifying appropriate terms. It is also not clear how well this record might represent the artist's intention in creating the work and how well this record might connect the artist's intended audience to the work.

\section{The Artist's View}

How well does the record describe Alpha to Omega? For this work the artist would opt for the longer, more descriptive record. However, even the more complete record stumbles on the fact that the work covers so many topics, often in a cursory or even free associational way, that it is difficult to represent what the book is "about." Indeed, it is not "about" some of the subjects listed, though they do figure in the flow of ideas in the text. The subtitle, On the Universe, aims at signaling the inclusiveness of the work (and points back to many ancient Greek scientific texts with that title). By contrast, the brief record leaves too much open to conjecture and may inadvertently narrow the audience for the book to those interested only in artists' books or examples of fine press printing. One would like a record that lets potential users know enough about the contents to indicate something of the range of ideas the work includes. Still, there does not seem to be an efficient way to indicate the character of the visual art in the book beyond describing processes and materials.

\section{Remaining Issues}

Here we see the tension between artist's intention and cataloger's interpretation. However, whether the catalog record accurately represents the artist's intention or not, the cataloger's first responsibility is to provide adequate access for potential 
users of the book. A middle ground between the brief and fuller records discussed above may be desirable, balancing the need for controlled vocabulary and fuller notes with time and budget constraints. Here institutional policy can benefit the cataloger, providing guidance regarding institutional priorities and desired levels of description.

Several institutions have created their own controlled vocabularies or even set up a database separate from the main online catalog in which to record metadata about artists' books. While the Art and Architecture Thesaurus and the RBMS Controlled Vocabularies do improve access to some formats, the advantage of these local systems is that they are tailored specifically to artists' books and can be customized to the specific collections being described. ${ }^{21}$ The deficiency of this approach is the staff time and resources required to implement a local authority file or database. It also does not address the need for consistency across catalogs.

Communication with the curators who are purchasing artists' books is essential to the cataloger understanding the intended use of the collection, what the curator considers to be particular strengths or priorities in the collection, and what information the curator might have from the artist or book dealer about individual volumes. It could be beneficial to have the curator request a description in the artists' words of certain aspects of their work. Johanna Drucker's expanded record form might be a good place to start. ${ }^{22}$

Conservation departments may be able to offer guidance on identifying and naming particular binding structures and may be able to recommend good reference sources as well. This is particularly helpful for the special collections cataloger who lacks an art background. Art libraries may also be able to provide both reference sources and cataloging advice. Indeed, this conversation between art libraries and special collections libraries should be happening at the national and international level.

The ARLIS manual on cataloging artists' books is an excellent resource, offering practical guidelines for describing artists' books according to AACR2. The basic principles of these guidelines-making creative and flexible use of the rules and the notes fields - are equally applicable to cataloging according to RDA. Despite the manual's utility, it is little used by special collections libraries. A common standard, used by both art and special collections libraries, would be beneficial to catalogers and users alike.

21. Dyer and Hibben, "Developing a Book Art Genre Headings Index," 60; Stover, "Categorizing the Unique," 15.

22. Drucker, "Critical Issues/Exemplary Works," 9-10. 
Also at the national level, a controlled vocabulary specific to artists' books would be a boon to artists' book catalogers, even if it was simply a compilation of appropriate terms from existing controlled vocabularies, such as Library of Congress Subject Headings, the Art and Architecture Thesaurus, and the RBMS Controlled Vocabularies. This would save individual institutions from having to create local authority lists from scratch, even if they decided to customize a list for their specific collections.

Finally, there has not been a concerted effort to provide training for cataloging artists' books other than at the local level. There are numerous courses on creating artists' books at institutions such as Minnesota Center for Book Arts and the San Francisco Center for the Book, and California Rare Book School offers a course on collecting artists' books, but there are no comparable courses in the special collections community available for describing artists' books. It may be that the lack of agreed-upon standards makes the teaching of such a course difficult. One cataloger's approach could vary greatly from another cataloger's approach, and the needs of individual institutions would come into play as well. But this is not so different from rare books cataloging, where even with agreed-upon standards, individual approaches can vary.

\section{Conclusion}

Through examining a particular artist's book, we have tried to show the advantages and disadvantages of different approaches to cataloging such works. Individual catalogers would benefit from institutional cataloging policies specifically for artists' books, local controlled vocabularies, and more communication with curators, conservators, and art librarians. However, the burden of improving access to artists' book collections should not lie with individual catalogers and institutions alone. As artists' book collections in special collections libraries grow, the need for training and national standards will also increase and must be met if we are going to provide access to these unique items. 